\title{
Influence of Bispectral Index Monitoring on Isoflurane Minimum Alveolar Concentration in Off Pump Cardiac Surgeries
}

\author{
Anagha M. V.1 , Manjunath R. Kamath ${ }^{2}$ \\ ${ }^{1}$ Department of Anaesthesiology, Rajarajewari Medical College and Hospital, Bengaluru, Karnataka, India. \\ 2Department of Anaesthesiology, K. S. Hegde Medical Academy, Mangaluru, Karnataka, India.
}

\section{ABSTRACT}

\section{BACKGROUND}

Off pump CABG is the most commonly performed cardiac surgical procedure involving multi vessel grafting through median sternotomy. Approach of lateral and posterior walls of heart for grafting, necessitates need for lifting or tilting heart producing elevated atrial pressures, fall in cardiac output and thus profound hypotension. Maintaining delicate balance between myocardial oxygen demand and supply is crucial to prevent myocardial insults and associated sequelae for which the mean arterial pressure is maintained $>70 \mathrm{mmHg}$ to facilitate adequate coronary perfusion pressure achieved by infusion of vasopressors like dobutamine and increased preload. Another strategy adopted by anaesthesiologist to limit this hypotension is by reducing isoflurane and thus cardiac surgical patients are prone for awareness. Awareness is the explicit recall of sensory perceptions during anaesthesia.

\section{METHODS}

We studied 40 patients with ASA physical status II \& III, between age group of 18 to 65 years scheduled for elective off pump CABG after institutional ethical committee clearance and written informed consent. Patients were randomly allocated into two groups of 20 each. Group 1 (isoflurane in oxygen given with BIS maintained at 55+/5 ) and Group 2 (isoflurane in oxygen given without BIS).Comparison of the two groups was done in terms of gender, age, height, weight, heart rate, hemodynamics, dial concentration, minimum alveolar concentration, drugs consumed, time to extubation and intraoperative awareness. Results were statistically analyzed using independent $t$ test, chi square test and Fischer exact test. Data was presented in terms of mean, median and standard deviation. The ' $p$ ' value of $<0.05$ was considered significant.

\section{RESULTS}

Heart rate, systolic blood pressure, diastolic blood pressure and mean arterial pressure were higher in Group 1 compared to Group 2. The dial concentration and minimum alveolar concentration were found to be statistically significant 5 minutes after intubation upto 4.5 hours of the cardiac surgical procedure with ' $p$ ' value $<0.05$. Amount of midazolam and propofol used in Group 1 was higher when compared to Group 2 while there was no statistical significance with use of opioid (fentanyl) or muscle relaxant (pancuronium). Time to extubation and intraoperative awareness were comparable between both the groups.

\section{CONCLUSIONS}

BIS monitoring reduces amount of isoflurane used along with the prevention of awareness in cardiac surgical patients. It helps not only the anaesthesiologist but also the other operation theatre personnel by preventing environmental pollution.

\section{KEY WORDS}

Off Pump Cardiac Surgery, BIS, Isoflurane, Minimum Alveolar Concentration
Corresponding Author: Dr. Manjunath R. Kamath, K. S. Hegde Medical Academy, Nityanandanagar, Deralakatte, Mangaluru, Karnataka, India.

E-mail: manjunathkamath@gmail.com

DOI: $10.14260 /$ jemds/2020/228

Financial or Other Competing Interests: None.

How to Cite This Article: Anagha MV, Kamath MR. Influence of bispectral index monitoring on isoflurane minimum alveolar concentration in off pump cardiac surgeries. J. Evolution Med. Dent. Sci. 2020;9(13):1058-1064, DOI: $10.14260 /$ jemds $/ 2020 / 228$

Submission 11-01-2020,

Peer Review 10-03-2020,

Acceptance 17-03-2020,

Published 30-03-2020.

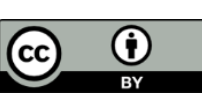




\section{BACKGROUND}

Off pump CABG is the most common performed cardiac surgery, involving multi vessel grafting and anaesthesia associated with it is known to have a high incidence of awareness. Awareness which is the unexpected and explicit recall of events in the intraoperative period is most commonly prevented by maintaining a deeper plane of anaesthesia by using a higher MAC of inhalational anaesthetic agent most commonly used among which is isoflurane. Isoflurane concentration is often reduced at the time of grafting especially involving lateral and posterior walls of heart, as they lift the heart during this step, which is invariably associated with hypotension and this might result in lighter plane of anaesthesia and hence awareness. Bispectral Index which is a EEG monitor, is an objective method of monitoring the depth of anaesthesia and hence prevent intraoperative awareness.

The present study was conducted to determine if BIS monitoring would reduce the isoflurane MAC and thus reduce the unnecessary excessive usage of isoflurane, prevent hypotension and yet prevent awareness in patients undergoing off pump CABG. Intraoperative awareness is the unexpected and explicit recall of events in the intraoperative period which are unpleasant and often distressing. ${ }^{1}$ Awareness during general anaesthesia maybe experienced by 1 or 2 cases out of every 1000 patients $(0.1-0.2 \%) .{ }^{2}$ The overall incidence is higher among obstetric and cardiac cases where the incidence is $0.4 \%$ and $1.1-1.5 \%$ respectively. ${ }^{3}$ In children the incidence of intraoperative awareness is $0.8-1.2 \%{ }^{4,5} \mathrm{In}$ order to address the qualitative aspects of awareness, a framework has been designed to classify the features of intraoperative awareness reports and this report is referred to as the Michigan Awareness Classification Instrument. ${ }^{6}$

Maintenance of adequate depth of anaesthesia is essential to prevent this awareness which can be achieved with most widely accepted BIS monitoring. BIS monitoring can reduce the requirement of anaesthetic drugs used and can have economic benefits along with prevention of environmental pollution. The present study was conducted to determine influence of BIS monitoring on Isoflurane Minimum Alveolar Concentration in patients undergoing Off pump cardiac surgeries. To determine if the requirement of isoflurane is reduced using BIS in comparison to non BIS monitoring.

\begin{tabular}{|l|c|}
\hline Class 0 & No awareness \\
\hline Class 1 & Isolated auditory perceptions \\
\hline Class 2 & Tactile perceptions (e.g. surgical manipulation or endotracheal intubation) \\
\hline Class 3 & Pain \\
\hline Class 4 & Paralysis (e.g. feeling one cannot move, speak or breathe) \\
\hline Class 5 & Paralysis and pain \\
\hline \multicolumn{2}{|c|}{ Classification of Intraoperative Awareness } \\
\hline
\end{tabular}

This instrument is being followed by investigators working on data in the American Society of Anesthesiologists Anaesthesia Awareness Registry.

\section{Risk Factors for Awareness}

Heightened risk of awareness has been attributed to two factors: patient- related and surgical factors. These include patients with genetic or acquired resistance to anaesthetic agents, patients who cannot tolerate high dose of anaesthetic agents due to poor cardiac reserve and in surgeries where anaesthetic doses are kept low, like in case of cardiac surgeries and in case of caesarean section under general anaesthesia. ${ }^{7}$
The most important risk factor attributed is the under dosing. ${ }^{8}$ Some patients may be physiologically resistant to amnesic or hypnotic effects of anaesthetic agents and this could be due to accelerated metabolism of the drugs in these individuals or due to pharmacodynamic variability in terms of receptor affinity alterations. ${ }^{9}$ Drug induced paralysis has also been shown to be a cause of incidence and severity of awareness ${ }^{10}$. Use of muscle relaxants is shown to modify the experience of awareness and the likelihood for development of post traumatic stress disorder. ${ }^{11}$

\section{Psychological Sequelae of Awareness}

It include anxiety, helplessness, panic, sleep disturbances, nightmares, post traumatic stress disorder and impending death. ${ }^{12}$

\section{Prevention of Awareness}

Intraoperative awareness can be prevented by making sure that each patient receives more than sufficient amount of anaesthetic agent throughout the period of general anaesthesia. Usefulness of brain monitor cannot be undermined when it comes to objectively prove adequate depth of anaesthesia and lack of awareness. The most commonly used monitor for this purpose is the electroencephalography (EEG). ${ }^{13}$

\section{Bispectral Index (BIS)}

It is the first Electroencephalographic (EEG) index introduced as monitor for assessment of depth of anaesthesia ${ }^{14}$. It measures the hypnotic component of anaesthesia only. In awake state BIS value range between 90 to 100 while in complete cessation of brain activity BIS score will be 0 which is known as flat line. ${ }^{15}$ BIS value between 40 to 60 indicates adequate depth of anaesthesia.

\section{Off Pump Cardiac Surgeries}

Displacement of heart during bypass grafting can result in arrhythmia intra operatively especially, reperfusion arrhythmia, hence, serum potassium is maintained at $>4.5$ mmol/litre. Magnesium can also be given to reduce the chances of arrhythmia. Anticoagulation is needed during off pump surgery to ensure the activated clotting time(ACT) is maintained at 200 to $300 \mathrm{~s}$. Heparin 1 to $2 \mathrm{mg} / \mathrm{Kg}$ is given before internal mammary artery is manipulated. Reversal of anticoagulation is done with protamine. Hypothermia should be avoided by using body warmer, warm IV fluids, and heat exchange device on the fresh gas flow.

\section{Outcome of OPCAB}

Rate of complications are less with off pump cardiac surgeries in comparison to on pump surgeries, though rate of morbidity and mortality are similar. ${ }^{16}$

\section{Isoflurane}

Due to the risk of isoflurane causing hypotension during cardiac surgery, it is used cautiously, and this can be a reason for the high incidence of awareness in cardiac surgeries.

\section{Minimum Alveolar Concentration}

It is defined as the minimum alveolar concentration of anaesthetic at 1 atmosphere (atm), which produces immobility in $50 \%$ of individuals subjected to noxious stimuli, 
usually skin incision. ${ }^{17}$ With the entry of paralyzing agent into anaesthesia practice, the need to measure anaesthetic potency became essential as the patient moved if he came too light and if deep, respiration became impaired and advent of concept of MAC helped to solve this problem

\section{Aim of the Study}

To determine if the requirement of isoflurane is reduced by using BIS in comparison to non BIS during off pump CABG

\section{Objectives of the Study}

1. Assess hemodynamic changes at skin incision, sternotomy and at various steps of cardiac surgery.

2. Assess time to extubation.

3. Assess the amount of anaesthetics and muscle relaxants used.

4. Assess the awareness levels.

\section{Literature Survey}

1. In the study by Muralidhar et al it was studied if BIS reduced the anaesthetic requirement in patients undergoing off pump CABG. This prospective clinical trial was performed in 40 patients undergoing elective off pump CABG. Patients either received is of luraneor propofol anaesthesia. They concluded that BIS guided anaesthesia reduces requirement of isoflurane by $35.2 \%$ and propofol by $32 \%$ for the performance of off pump CABG and they also said that this could be extrapolated in terms of saving agent and reduced cardiac depression. ${ }^{18}$

2. Nitzschke et al did a prospective controlled two arm clinical trialon 60 elective on pump cardiac surgery patients by delivering sevoflurane under BIS guidance and determine sevoflurane plasma concentration (SPC). They concluded that BIS guided sevofluranetitration reduces the SPC and decrease snoradrenaline administration compared with routine care during on pump cardiac surgeries. ${ }^{19}$

\section{METHODS}

This is a randomized control trial conducted among adult patients aged 18-70 years, belonging to ASA PS (American Society of Anesthesiologists physical status) 1, 2 and 3, scheduled for elective cardiac surgeries in K.S. Hegde Hospital from January 2017 to August 2018.

\section{Sample Size}

To compute sample size, the technique of estimation of single proportion was used. Using SPSS software version 16.0 the following formula was derived to determine sample size-

$$
n=\frac{Z^{2} 1-\frac{a}{2} P(1-P)}{d^{2}}
$$

$a=$ level of significance (5\%)

$\mathrm{P}=$ Anticipated proportion $(35 \%)$

$\mathrm{d}=$ precision $(15 \%)$

$n=(1.96)^{2} 35(100-35)(15)^{2}$

$\mathrm{n}=40$
Calculated sample size is 40 with 20 patients in each group.

\section{Selection Method}

Patients were randomly allocated by closed envelope technique into 2 groups namely

1. Group 1: Isoflurane in oxygen given with BIS maintained at $55+/-5$

2. Group 2: Isoflurane in oxygen given without BIS

\section{Inclusion Criteria}

18 years' to70 years who are admitted for elective cardiac surgeries.

\section{Exclusion Criteria}

1. Off-pump CABG converted to conventional CABG with $\mathrm{CPB}$ at any point should the patient not tolerate the period of ischaemia required to complete the graft or for surgical reasons.

2. Left ventricular aneurysm.

3. Ejection fraction of $<35 \%$.

4. Ischaemic mitral regurgitation.

5. Patients with difficult airway.

6. Dilated cardiomyopathies.

7. Renal/ hepatic dysfunction.

8. Psychiatry patients.

9. Patients on CNS medications.

After obtaining approval of institutional ethics committee, this prospective randomized trial was done. All patients were kept nil per oral as per standard guidelines Antihypertensive and antianginal medications continued until morning of surgery. Premedication with oral diazepam $10 \mathrm{mg}$ if $>50 \mathrm{~kg}$ and $5 \mathrm{mg}$ if $<50 \mathrm{~kg}$ at bed time on night prior to surgery and 2 hours prior to anaesthesia and surgery After shifting to operation theatre patient was administered oxygen by face mask and monitoring of ECG (5lead) with automated ST segment analysis (3M monitoring ECG machine) and pulse oximetry were initiated

The two channel EEG signal for the BIS was captured using cutaneous electrodes (Quatro Sensor- T1860I06) positioned as recommended by the manufacturer. To minimize artifactual error, the BIS score was recorded only in the absence of possible confounding signals. BIS values during electrocautery were not taken into consideration during the study. A target BIS of 50-60 was maintained throughout the intraoperative period by adjusting dial concentration settings

A 14G/16G IV cannula inserted on dorsum of right hand; 20 gauge switch arterial cannula was introduced into radial artery for monitoring of arterial pressure and obtaining blood for analysis. General anaesthesia was induced after preoxygenation of patient with $100 \%$ oxygen for 3 minutes, using a combination of fentanyl $5 \mathrm{mcg} / \mathrm{Kg}$, midazolam 50 $\mathrm{mcg} / \mathrm{Kg}$ and propofol $1 \mathrm{mg} / \mathrm{Kg}$. Endotracheal intubation was performed after administration of pancuronium bromide 0.1 $\mathrm{mg} / \mathrm{Kg}$ and mechanical ventilation was initiated.

Placement of tube was confirmed by 5-point auscultation and $\mathrm{EtCO}_{2}$. A central line was secured into the right internal jugular vein using 7 French triple lumen catheter. Low flow technique (fresh gas flow of $1 \mathrm{l} / \mathrm{min}$ ) using anaesthesia machine (Aestiva 5 Datexohmeda) to achieve ETCO2 of 35+/$3 \mathrm{mmHg}$ was used. Hemodynamic parameters were 
maintained within $20 \%$ of basal value with nor epinephrine, nitroglycerine and atropine. Intraoperative hypothermia prevented by using warm fluids (IV fluids), warm airflow at 40-degree Celsius (Hemotherm, Cincinnati Sub Zero). Filling pressure and fluid balance were maintained by using crystalloids and colloids. Isoflurane was administered in group 1 and 2 through Isotech 7 vapourizer. At the time of sternal closure 1g IV paracetamol was given. Amount of inotropes, inhalational agents, muscle relaxants and any additional agent if used were tabulated and complications if any were noted. At the end of procedure patient was shifted to cardiac intensive care unit with endotracheal tube in situ.

The following parameters were monitored: heart rate (beats/min), systolic blood pressure ( $\mathrm{mm} \mathrm{Hg}$ ), disatolic blood pressure (mm $\mathrm{Hg}$ ), mean arterial pressure ( $\mathrm{mm} \mathrm{Hg}$ ), arterial oxygen saturation (Sp02), dial concentration (\%), minimum alveolar concentration at preinduction, pre intubation, 1 minute after induction, 3 minutes after induction, 5 minutes after induction and thereafter every 10 minutes upto 30 minutes and thereafter every half hour upto the end of the surgical procedure. All patients were ventilated post operatively for 2-4 hours and tracheal extubation performed after satisfying criteria for extubation (namely patient being hemodynamically stable, good spontaneous respiratory efforts, neurological recovery, conscious, warm, not bleeding excessively and fully recovered from effects of neuromuscular blocking agents. Patients were interviewed 18 hours after extubation. After an initial introduction, a structured interview was done.

Following set of standard questions were asked-

1. What was the last thing you remember before surgery?

2. What was the first thing you can remember after surgery?

3. Can you remember anything in between these two periods?

4. Did you have any dreams during your operation?

If patient indicated that he/she did not have explicit memory of intraoperative events while answering these questions no further questions were asked. If the patient's answer was YES, then the following set of sub questions were asked-
a. What did you feel? Sounds, touch, pain, paralysis?
b. How long did it last?
c. How did you react?
d. Have these been of any consequences to you?

If patient suggested that he/she suffered from awareness under anaesthesia he/she was visited by the attending anaesthetist to discuss, explain perioperative events, answer patient's questions sympathetically and refer patient for psychological counselling if required

\section{Statistical Analysis}

The collected information was summarized by using frequency and percentage for qualitative data. Mean and standard deviation for quantitative data. To compare the outcome measures between two groups, unpaired t test was used. If data is not following normal distribution, MannWhitney $U$ test was used for comparing qualitative data, chi square test and Fischer' sex act test were used. 'p' value of $<0.05$ was considered statistically significant.

\section{RESULTS}

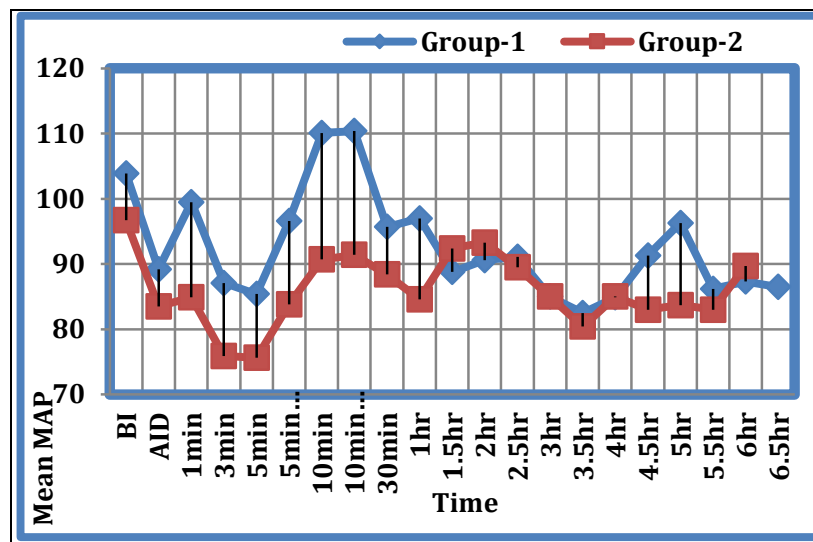

Figure 1. Major Part of the Cardiac Surgery MAP Remained Higher in Group 1 in Comparison to Group 2
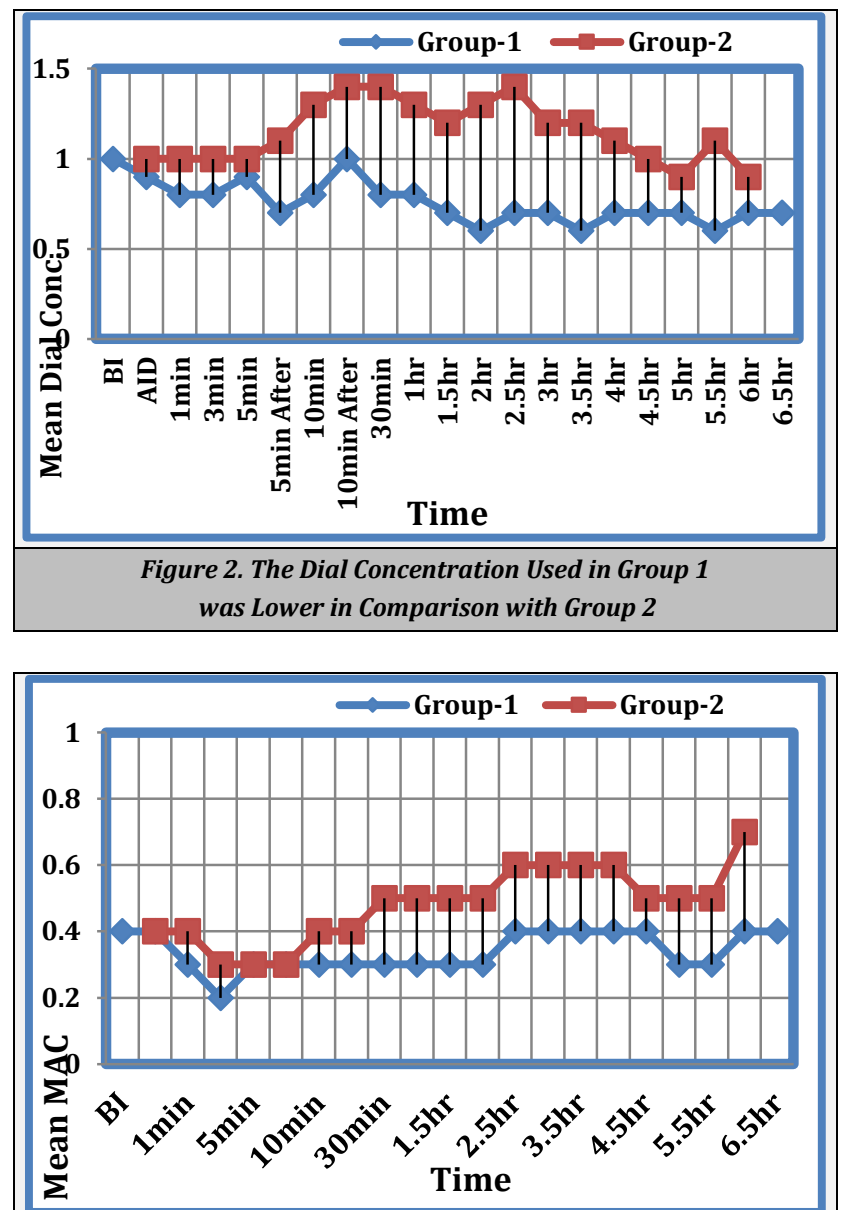

Figure 3. MAC Values Are Lower in Group 1 in Comparison to Group 2 in Most Part of the Duration of Cardiac Surgery 


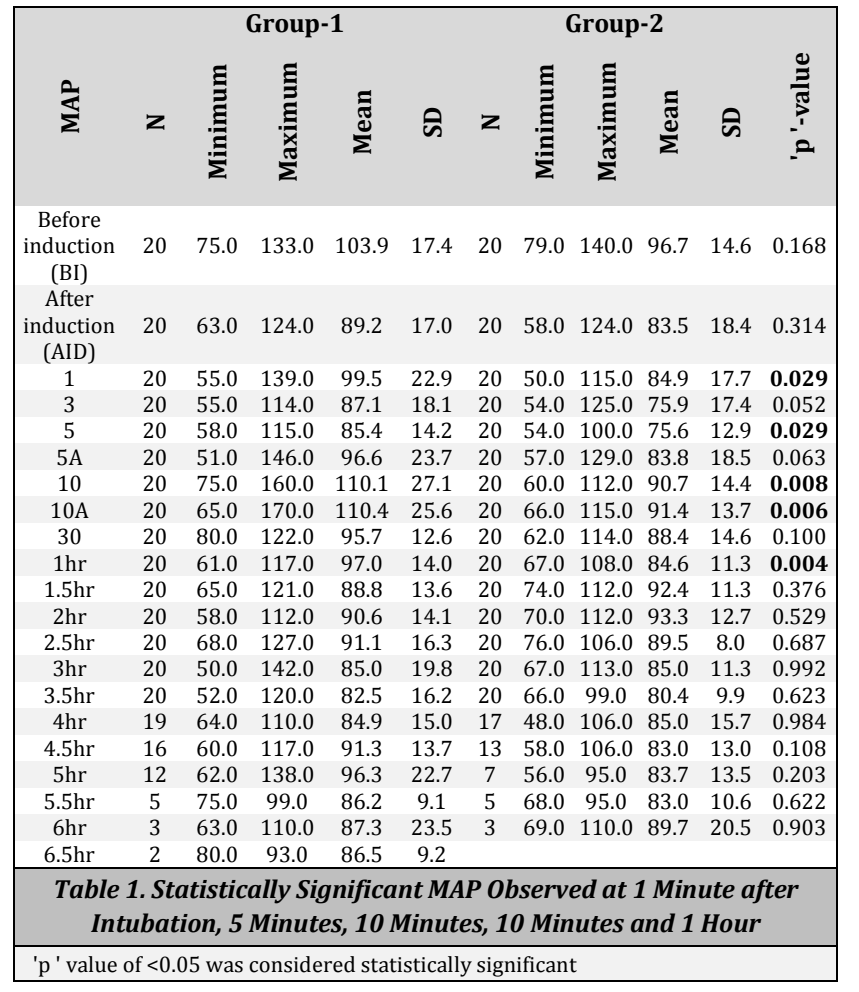

\begin{tabular}{|c|c|c|c|c|c|c|c|c|c|c|c|}
\hline \multirow[b]{2}{*}{$\frac{\ddot{\Xi}}{\text { ப் }}$} & \multirow[b]{2}{*}{ z } & \multicolumn{3}{|c|}{ Group-1 } & \multicolumn{6}{|c|}{ Group-2 } & \multirow[b]{2}{*}{ 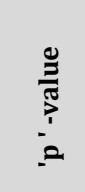 } \\
\hline & & 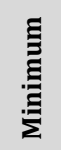 & 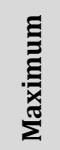 & $\sum_{\Sigma}^{\Xi \Xi}$ & कิ & $z$ & $\stackrel{\Xi}{\Xi}$ & 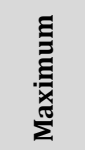 & $\sum_{\Sigma}^{\pi}$ & की & \\
\hline $\begin{array}{c}\text { Before } \\
\text { induction } \\
\text { (BI) }\end{array}$ & 3 & 1.0 & 1.0 & 1.0 & 0.0 & & & & & & \\
\hline $\begin{array}{l}\text { After } \\
\text { induction } \\
\text { (AID) }\end{array}$ & 15 & 0.2 & 1. & 0.9 & 0.2 & 14 & 1.0 & 1.0 & 1.0 & 0.0 & 0.343 \\
\hline 1 & 20 & 0.2 & 2.0 & 0.8 & 0.4 & 1 & 10 & 1.5 & 1.0 & 0.1 & 0.055 \\
\hline 3 & 2 & 0.1 & 3.0 & 0.8 & 0.7 & 2 & & & 1.0 & 1 & 0.149 \\
\hline 5 & & 0.1 & 3.0 & 0.9 & 0.9 & 2 & & & .0 & .0 & 0.816 \\
\hline $5 A$ & 2 & 0.2 & 2.0 & 0.7 & 0.5 & $1 \mathrm{c}$ & & & 1.1 & 0.2 & 0.008 \\
\hline 10 & 0 & 0.2 & 2.0 & 0.8 & 0.6 & 20 & 0.8 & 2 & 1.3 & .4 & 0.018 \\
\hline $10 \mathrm{~A}$ & 2 & 0.2 & 2.0 & 1.0 & 0.6 & & & & 1.4 & 0.5 & 0.023 \\
\hline 30 & 0 & 0.2 & 2.0 & 0.8 & 0.5 & 20 & & & 1. & 0.5 & $<0.001$ \\
\hline $1 \mathrm{hr}$ & & 0.2 & 2.0 & 0.8 & 0.4 & 20 & 0. & & 1.3 & 0.4 & 0.001 \\
\hline $1.5 \mathrm{hr}$ & 20 & 0.2 & 2.0 & 0.7 & 0.4 & 20 & 0 & 2.5 & 1.2 & 0.5 & 0.002 \\
\hline & 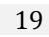 & 02 & 10 & 0.6 & 0.3 & & & & 13 & .4 & $<0.001$ \\
\hline $2.5 \mathrm{hr}$ & 20 & 0.20 & 1.00 & 0.7 & 0.3 & 20 & 1.00 & 2.50 & 1.4 & 0.5 & $<0.001$ \\
\hline & 0 & 0.2 & 2.0 & 0.7 & 0.4 & 20 & 10 & 20 & 1.2 & 0.3 & $<0.001$ \\
\hline $3.5 \mathrm{hr}$ & 20 & 0.2 & 1.0 & 0.6 & 0.3 & 20 & 0.6 & 2.0 & 1.2 & 0.4 & $<0.001$ \\
\hline $4 \mathrm{~h}$ & 19 & 0.2 & 1.2 & 0.7 & 0.3 & 17 & 0.6 & & 1.1 & 0.3 & $<0.001$ \\
\hline $4.5 \mathrm{hr}$ & & 0 & 10 & 07 & 0.3 & 13 & & & 10 & 0.1 & 0.005 \\
\hline $5 \mathrm{l}$ & 12 & 0.2 & 1.0 & 0.7 & 0.3 & 7 & 0.6 & 1.0 & 0.9 & 0.2 & 0.079 \\
\hline $5.5 \mathrm{hr}$ & 5 & 0.2 & 1.0 & 0.6 & 0.3 & 5 & 0.6 & 2.0 & 1.1 & 0.5 & 0.086 \\
\hline $6 \mathrm{hr}$ & 3 & 0.4 & 1.0 & 0.7 & 0.3 & 3 & 0.6 & 1.0 & 0.9 & 0.2 & 0.417 \\
\hline $6.5 \mathrm{hr}$ & 2 & 0.6 & .8 & 0.7 & 0.1 & & & & & & \\
\hline \multicolumn{12}{|c|}{$\begin{array}{l}\text { Table 2. Dial Concentration Shows Statistical Significance from } \\
5 \text { Minutes after up to } 4.5 \text { Hours into the Cardiac Surgery }\end{array}$} \\
\hline & & & & & & & & & & & \\
\hline
\end{tabular}

\section{DISCUSSION}

Off pump CABG also called as the beating heart surgery is the most common cardiac surgical procedure performed, which involves multi vessel grafting through median sternotomy which allows visualization of all the coronary vessels. Surgical access to LAD is easy through the sternotomy, but to approach

\begin{tabular}{|c|c|c|c|c|c|c|c|c|c|c|c|}
\hline \multirow[b]{2}{*}{$\sum_{\Sigma}^{u}$} & \multirow[b]{2}{*}{$\mathbf{z}$} & \multicolumn{3}{|c|}{ Group-1 } & \multirow[b]{2}{*}{ ڤิ } & \multirow[b]{2}{*}{$z$} & \multicolumn{3}{|c|}{ Group-2 } & \multirow[b]{2}{*}{ คิ } & \multirow[b]{2}{*}{$\begin{array}{l}\frac{0}{\pi} \\
\frac{\pi}{1} \\
-2\end{array}$} \\
\hline & & $\underset{\Sigma}{\Xi}$ & $\underset{\sum}{\stackrel{\Xi}{\Xi}}$ & 胥 & & & $\stackrel{\Xi}{\Xi}$ & 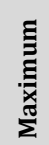 & §ָ & & \\
\hline $\begin{array}{c}\text { Before } \\
\text { induction(BI) }\end{array}$ & 3 & 0.3 & 0.7 & 0.4 & 0.2 & & & & & & \\
\hline $\begin{array}{c}\text { After } \\
\text { induction(AID) }\end{array}$ & 15 & 0.2 & 0.7 & 0.4 & 0.2 & 13 & 0.2 & 0.7 & 0.4 & 0.1 & 0.858 \\
\hline 1 & 20 & 0.1 & 0.8 & 0.3 & 0.2 & 17 & 0.2 & 0.7 & 0.4 & 0.1 & 0.068 \\
\hline 3 & 20 & 0.1 & .5 & 0.2 & 0.1 & 19 & 0.1 & 6 & 3 & 0.1 & 0009 \\
\hline 5 & 20 & 0.1 & 0.7 & 0.3 & 0.2 & 19 & 0.2 & .5 & 0.3 & 0.1 & 0.339 \\
\hline $5 \mathrm{~A}$ & 20 & 0.1 & 0.5 & 0.3 & 0.2 & 19 & 0.1 & .5 & 0.3 & 0.1 & 0.342 \\
\hline 10 & 20 & 0.1 & . & 0.3 & 0.2 & 19 & 0.1 & 6 & 0.4 & 0.1 & 0.076 \\
\hline $10 \mathrm{~A}$ & 20 & 0.1 & 0.8 & 0.3 & 0.2 & 19 & 0.2 & 9 & 0.4 & 0.2 & 0.030 \\
\hline 30 & 20 & 0.1 & 0.6 & 0.3 & 0.1 & 19 & 0.2 & 0.8 & 0.5 & 0.2 & $<0.001$ \\
\hline $1 \mathrm{hr}$ & 20 & 0.2 & 0.6 & 0.3 & 0.1 & 19 & 0.2 & 0.8 & 0.5 & 0.2 & $<0.001$ \\
\hline $1.5 \mathrm{hr}$ & 20 & 0.1 & 0.6 & 0.3 & 0.1 & 19 & 0.3 & 0.8 & 0.5 & 0.2 & $<0.001$ \\
\hline $2 \mathrm{~b}$ & 20 & 0.1 & 0. & 0.3 & 0.2 & 19 & 0.3 & 3 & 5 & 0.2 & $<0.001$ \\
\hline $2.5 \mathrm{hr}$ & 20 & 0.1 & 0.5 & 0.4 & 0.1 & 19 & 0.4 & 0.8 & 0.6 & 0.1 & $<0.001$ \\
\hline $3 \mathrm{hr}$ & 20 & 0.1 & 0.7 & 0.4 & 0.2 & 19 & 0.4 & 1.0 & 0.6 & 0.2 & $<0.001$ \\
\hline $3.5 \mathrm{hr}$ & 20 & 0.1 & 0.7 & 0.4 & 0.2 & 19 & 0.4 & 0.9 & 0.6 & 0.1 & $<0.001$ \\
\hline & 19 & 0.1 & 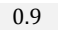 & 0.4 & 0.2 & 18 & 0.4 & 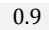 & 0.6 & 0.1 & 0.001 \\
\hline $4.5 \mathrm{hr}$ & 16 & 0.1 & 0.7 & 0.4 & 0.2 & 14 & 0.3 & 0.8 & 0.5 & 0.1 & 0.004 \\
\hline $5 \mathrm{hr}$ & 12 & 0.1 & 0.5 & 0.3 & 0.1 & 8 & 0.3 & 0.5 & 0.5 & 0.1 & 0.018 \\
\hline $5.5 \mathrm{hr}$ & 5 & 0.1 & 0.4 & 0.3 & 0.1 & 6 & 0.3 & 0.6 & 0.5 & 0.1 & 0.040 \\
\hline $6 \mathrm{hr}$ & 3 & 0.3 & 0.5 & 0.4 & 0.1 & 3 & 0.6 & 0.8 & 0.7 & 0.1 & 0.021 \\
\hline $6.5 \mathrm{hr}$ & 2 & 0.3 & 0.4 & 0.4 & 0.1 & & & & & & \\
\hline \multicolumn{12}{|c|}{$\begin{array}{c}\text { Table 3. MAC Values are Found to be Statistically Significant } 3 \\
\text { Minutes after Intubation, } 10 \text { Minutes after, up to } 6.5 \text { Hours Which is } \\
\text { up to the End of the Surgery }\end{array}$} \\
\hline
\end{tabular}

lateral or posterior wall, heart needs to be lifted or tilted which produces an elevated trial pressure, with severe fall in cardiac output (cardiac index $<2 \mathrm{l} / \mathrm{min} / \mathrm{m}^{2}$ ), along with it the application of octopus (stabilizing device) restricts localized wall contractility and causes reduced ventricular wall dimensions and hence profound hypotension. ${ }^{20}$

In this situation it becomes necessary to formulate a strategy to balance myocardial oxygen demand and oxygen supply. This can be achieved by keeping the myocardial oxygen demand as minimal as possible and maintain mean arterial pressure $>70 \mathrm{~mm} \mathrm{Hg}$, hence maintain coronary artery perfusion pressure by means of infusion of vaso pressors liked obutamine and increase the preload. In addition to the above measures, anaesthesiolog is tend to reduce is of lurane administered to the patient because is of lurane itself decreases systemic vascular resistance and produces hypotension and thus chances of awareness is heightened by lighter plane of anaesthesia.

The most widely used monitor to assess the depth of anaesthesia and thus prevent awareness is the BIS developed by Aspect Medical System in 1994 which processes a single frontal EEG signal and produces a dimensionless number, which when falls in the range of 40 to 60 indicates adequate plane of anaesthesia. ${ }^{21}$ The present study was conducted to determine the influence of BIS on the isoflurane MAC in patients undergoing off pump CABG. We studied 40 patients with ASA physical status II and III, between age group of 18 to 65 years scheduled for elective off pump CABG.

Patients were randomly allocated into 2 groups of 20 each

1. Group 1: Patients were given Isoflurane with oxygen with usage of BIS maintained at 55+/- 5 .

2. Group 2: Patients were given Isoflurane with oxygen without usage of BIS maintaining mean arterial pressure between 60 to $120 \mathrm{mmHg}$. 
Both the groups were comparable with respect to age, gender, weight, height and ASA physical status. No patients were excluded from the study Dial concentration which is the target number on the vapourizer dial to deliver inhalational anaesthetic compared between the two groups showed a statistically significant variation from 5 minutes after up to about 4.5 hours into the surgical procedure with much lesser dial concentration used in Group 1 in comparison to group 2. There have been very less studies which have tried to analyze the dial concentration variations with and without use of BIS Minimum alveolar concentration shows a similar pattern to that of dial concentration with statistically significant reduction in almost the entire duration of cardiac surgery between 5 minutes after intubation upto 4.5 hours into the cardiac surgical duration in Group 1 compared to Group 2 which proves that the amount of isofluraneutilized in Group 1 is significantly lower in comparison to group 2.

Gan et al have shown a reduced use of propofol and faster recovery in comparison to standard practice and hence it has potential economic benefits. ${ }^{22}$ Muralidhar $\mathrm{K}$ et al have shown that BIS monitoring reduces anaesthetic requirements in patients undergoing off pump cardiac surgeries without risk of awareness and they recommend the routine use of BIS in clinical practice Halogenated inhalational anaesthetic agents such as isoflurane are proven to be greenhouse gases. Hence we demonstrated that with use of BIS and consequently reducing the amount of isofluraneutilized we are saving the adverse consequences of environmental pollution Intraoperative awareness in both the groups were comparable and no-significant difference was found, with 2 patients in Group 1 having intraoperative awareness and 1 patient in Group 2 having intraoperative awareness. Hence, we derive that intraoperative awareness does not occur in either with use of BIS or without the use of BIS. Muralidhar K et al demonstrated that the use of BIS reduces the risk of intraoperative awareness though they do not find whether there was awareness in the conventional group. ${ }^{19}$

\section{Summary}

The present study was conducted to determine the influence of Bispectral Index Monitoring on the isoflurane minimum alveolar concentration in patients undergoing off pumpcardiac surgeries. We studied 40 patients with ASA physical status II and III, between age group of 18 to 65 years scheduled for elective off pump CABG. The patients were randomly allocated into two groups of 20 each. Group 1 (isoflurane in oxygen with BIS maintained at 55+/-5) and Group 2 (isoflurane in oxygen without BIS). Comparison of the two groups was done interms of the hemodynamic variations, dial concentration, minimum alveolar concentration, drugs used, time to extubation and intraoperative awareness. Results were statistically analyzed using independent $t$ test for outcome measures. For comparing qualitative data Chi square test and Fischer exact test was used. If the data did not follow normal distribution, Mann Whitney $\mathrm{U}$ test was used. The collected information was summarized using frequency and percentage for qualitative data and mean and standard deviation for quantitative data. We found that the heart rate, systolic blood pressure, diastolic blood pressure and mean arterial pressure were higher in Group 1 when compared to Group 2 ('p' value<0.05). Dial concentration and the minimum alveolar concentration of isoflurane used in Group 1 was much lesser than that in Group 2 almost throughout the surgical procedure time (' $p$ ' value $<0.05$ ). The amount of midazolam and propofol used in Group 1 was higher than in Group 2 while time to extubation and intraoperative awareness were identical in both Group 1 and Group 2.

\section{CONCLUSIONS}

BIS index as a monitor used in off pump cardiac surgeries is useful in reducing the amount of inhalational anaesthetic agent utilized, while maintaining adequate depth of anaesthesia and its usage as a routine monitor during cardiac surgeries can go along way in helping the anaesthesiologist, by judicious usage of anaesthetic agents and also the patient by preventing awareness. By its ability to reduce the use of anaesthetic agent, indirectly reduces environmental pollution and can protect operation theatre personnel from the hazards of prolonged exposure.

\section{REFERENCES}

[1] Avidan M, Jacobsohn E, Glick D, et al. Prevention of intraoperative awareness in a high-risk surgical population. N Engl J Med 2011;365(7):591-600.

[2] KertaiM, Whitlock E, Avidan M. Brain monitoring with electroencephalography and the electroencephalogramderived bispectral index during cardiac surgery. Survey of Anesthesiology. 2012;56(5):210-212.

[3] Mashour G, Orser B, Avidan M. Intraoperative awareness. Anesthesiology. 2011;114(5):1218-33.

[4] Black S. The incidence of intraoperative awareness in children: childhood awareness and recall evaluation. Yearbook of anesthesiology and pain management. 2010;2010:144-145.

[5] Lydic R, Biebuyck J. II Sleep neurobiology: relevance for mechanistic studies of anaesthesia. Br. J.Anaesth. 1994;72(5):506-508.

[6] Ghoneim M, Block R, Haffarnan M, Mathews M. Awareness during anesthesia: risk factors, causes and sequelae: A review of reported cases in the literature. Anesth.Analg. 2009;108(2):527-535.

[7] Paech MJ, Scott KL, Clavisi O, Chua S, McDonnell N, ANZCA Trials Group: A prospective study of awareness and recall associated with general anaesthesia for caesarean section. Intl J ObstetAnesth 2008; 17:298-303

[8] Saucier N, Walts L, Moreland J. Patient Awareness during Nitrous Oxide, Oxygen, and Halothane Anesthesia. Anesth.Analg. 1983;62(2):239-240.

[9] Lennmarken C, Sydsjo G. Psychological consequences of awareness and their treatment. Best Practice \& Research Clinical Anaesthesiology. 2007;21(3):357-367.

[10] Bennett C, Voss L, Barnard J, Sleigh J. Practical use of the raw electroencephalogram waveform during general anesthesia: The art and science. Anesth.Analg. 2009;109(2):539-550. 
[11] Castro A, Amorim P, Nunes CS: Modeling state entropy of the EEG and auditory evoked potentials: Hypnotic and analgesic interactions. Conf Proc IEEE Eng Med Biol Soc 2007; 2007:1949-52

[12] Rampil I. A primer for EEG signal processing in anesthesia. Anesthesiology. 1998;89(4):980-1002.

[13] Rosow C, Manberg P. Bispectral index monitoring. Anesthesiology Clinics of North America 2001;19(4):94766.

[14] Kelleher A, Gothard J. Anaesthesia for off-pump coronary artery surgery. Br J Anaesth 2004;92(3):324-6.

[15] Merkel G, Eger EI 2nd. A comparative study of halothane and halopropane anesthesia including method for determining equipotency. Anesthesiology 1963;24(3):346-57.

[16] Eger EI 2nd, Saidman LJ, Brandstater B. Minimum alveolar anesthetic concentration a standard of anesthetic potency. Anesthesiology 1965;26(6):756-63.

[17] Muralidhar K, Banakal S, Murthy K, et al. Bispectral indexguided anaesthesia for off-pump coronary artery bypass grafting. Annals of Cardiac Anaesthesia 2008;11(2):10510.
[18] Vance JL, Shanks AM, Woodrum DT. Intraoperative bispectral index monitoring and time to extubation after cardiac surgery: secondary analysis of a randomized controlled trial. BMC Anesthesiology 2014;14(1):79.

[19] Myles P, Leslie K, McNeil J, et al. Bispectral index monitoring to prevent awareness during anaesthesia: the B-aware randomised controlled trial. The Lancet 2004;363(9423):1757-63.

[20] Shafiq F, Naqvi HI, Ahmed A. Effects of bispectral index monitoring on isoflurane consumption and recovery profiles for anesthesia in an elderly Asian population. Journal of Anaesthesiology, Clinical Pharmacology 2012;28(3):348-52.

[21] Iselin-Chaves IA, Flaishon R, Sebel PS, et al. The effect of the interaction of propofol and alfentanil on recall, loss of consciousness and the bispectral index. Anesth Analg 1998;87(4):949-55.

[22] Langbein T, Sonntag H, Trapp D, et al. Volatile anaesthetics and the atmosphere: atmospheric lifetimes and atmospheric effects of halothane, enflurane, isoflurane, desflurane and sevoflurane. Br J Anaesth 1999;82(1):66-73 